\section{Rational therapy publication rate correlates with wealth of a society}

Dragan R. Milovanovic ${ }^{1}$

Slobodan M. Jankovic ${ }^{1}$

${ }^{1}$ Department of Pharmacology, Toxicology and Clinical Pharmacology, Faculty of Medical Sciences University of Kragujevac.

Two recent articles published in the consecutive issues of the Journal suggested that health professionals in Brazil have recently showed the rising interest for rational therapeutics including medical and economic consequences of widely prescribed drugs $^{1,2}$.Inspired with these efforts and taking into account limited resources of healthcare systems in many countries as well as recent worldwide financial crisis ${ }^{3}$ we decided to investigate whether there is a correlation between rational therapy publication rate and national indicators of welfare and healthcare investments.

We have taken some of the indicators from the World Bank internet database of countries: total population (for 2012), gross domestic product per capita (GDPpc, for 2012) and health expenditure per capita (HEpc, for 2011). We have also retrieved the journal indexing databases, Pubmed and Scopus, with appropriate key words (rational, treatment, management, therapeutics, pharmacotherapy, drug, therapy) limiting to the title field and using Boolean operators "AND" (rational) and "OR" (others). The total search was narrowed with a country name (the world as a whole was also included) and number of articles was standardized per million inhabitants (publication per million-Ppm). In general, the search adjustments were performed only in exceptional cases, taking into account a country's specificity and data outliers. Our analysis included only complete tripartite country's data per a database, excluding those outside 95 percentiles of $\mathrm{Ppm}$ which gave 75 pairs from PUBMED and 128 ones from SCOPUS database. The data distributions for all three parameters were highly skewed and $\log _{10}$ transformation converted them to normal distribution pattern. The results showed high correlation of Ppm with both GDPpc (Pearson $\mathrm{r}=0.598, \mathrm{p}<0.001$; $\mathrm{r}=$ $0.638, \mathrm{p}<0.001)$ and HEpc $(\mathrm{r}=0.642, \mathrm{p}<0.001$; $\mathrm{r}=0.679, \mathrm{p}<0.001$ ) (Figure 1). In addition, we found statistically significant linear regressions in all four sets of data and it is illustrated with the coefficients of determination $\left(r^{2}\right)$ shown next to the data series in Figure $1(\mathrm{p}<0.001)$.
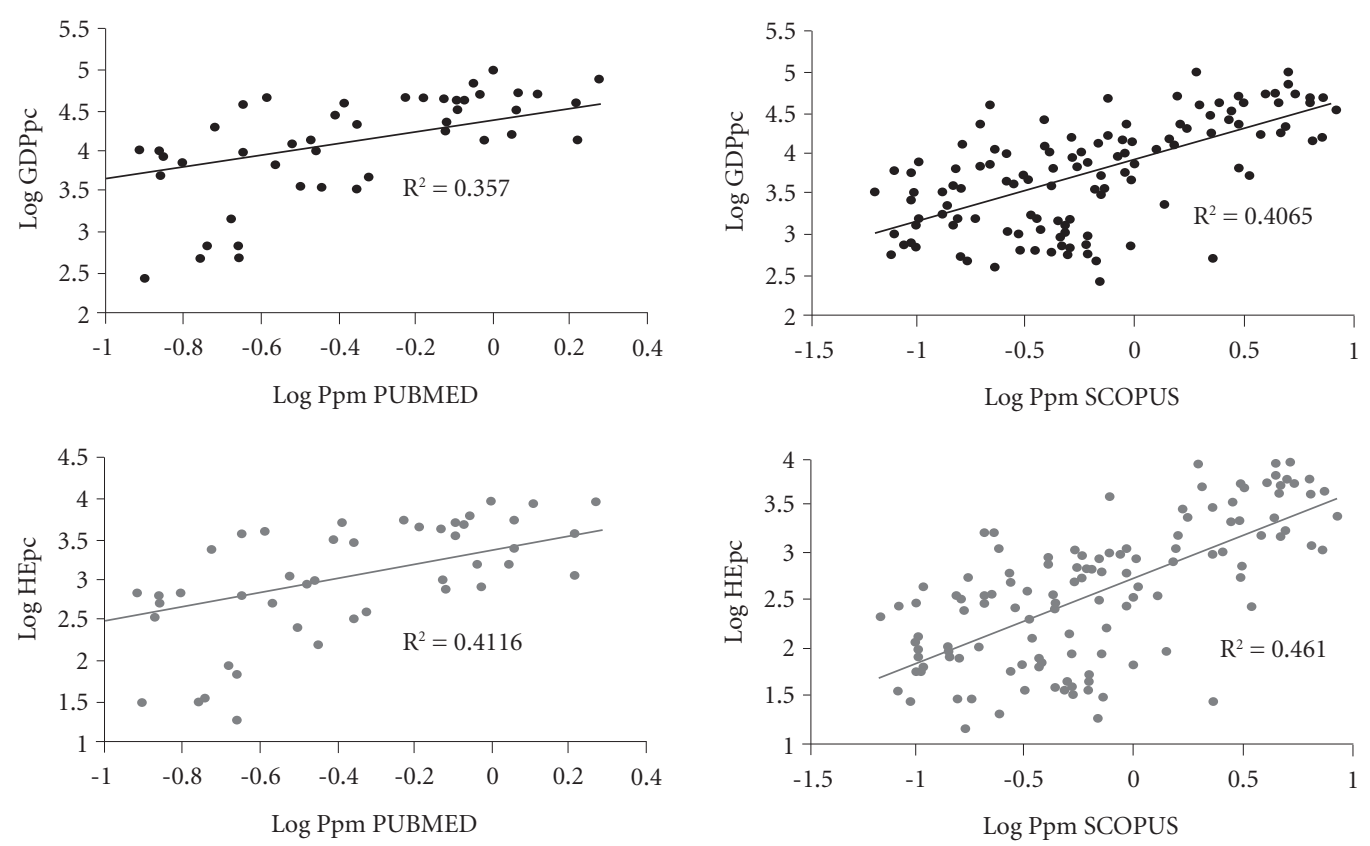

Figure 1. Relationships between $\log _{10}$ transformed data of the number of published papers in the field of rational therapy standardized per million inhabitants (Log Ppm), the gross domestic product per capita (Log GDPpc) and the health expenditure per capita (Log HEpc), for 75 (PUBMED search) and 128 countries (SCOPUS search) including the world population, too. 
We propose that the rational therapy policy concerning both drugs and other treatment strategies should be thoroughly developed on a national level in order to give additional benefits, including wide range of medical and non-medical (indirect) gains. Relatively moderate investments in rational therapy choices, and follow-up, will increase overall well-being (quality of life) of a country's inhabitants which, finally, will return the initial assets through increased productivity and monetary wealth. Poor and transitional countries must brake vicious circle of wasting health resources using treatments with unfavourable cost-effectiveness ${ }^{4}$. Instead, they should rigorously implement principles of rational therapy as initially proposed by the most respectable world health authorities and, in recent times, by advocates of evidence based medicine $e^{5}$. Of course, our preliminary analysis is just an initial observation and its results must be further explored with more comprehensive research design in the future.

\section{Thanks}

Authors thanks to Ministry of Education, Science and Technological Development of Republic of Serbia for partial support through the research grant.

\section{References}

1. Mendes LV, Luiza VL, Campos MR. Rational use of medicines by individuals with diabetes mellitus and arterial hypertension in the municipality of Rio de Janeiro, Brazil. Cien Saude Colet 2014; 19(6):1673-1684.

2. Mota DM, de Oliveira MG, Bovi RF, Silva SF, Cunha JA, Divino JA. Are there irrationalities in the consumption of anti-obesity drugs in Brazil? A pharmaco-econometric analysis of panel datasets. Cien Saude Colet 2014; 19(5):1389-1400.

3. Stuckler D, McKee M. There is an alternative: public health professionals must not remain silent at a time of financial crisis. Eur J Public Health 2012; 22(1):2-3.

4. Mackenbach JP, Karanikolos M, McKee M: The unequal health of Europeans: successes and failures of policies. Lancet 2013; 381(9872):1125-1134

5. Promoting rational use of medicines saves lives and money, WHO experts say. Saudi Med J 2004; 25(9):13091130. 